\title{
Photodegradation for Tetracycline Chloride from Water by using Electric Arc Furnace Dust
}

\author{
Sabah S. Ibrahim \\ Chemistry Department, Central Lab for Environmental Quality Monitoring, National Water Research Center, Delta Barrages, Egypt
}

Address For Correspondence:

Sabah S. Ibrahim, Chemistry Department, Central Lab for Environmental Quality Monitoring, National Water Research Center, Delta Barrages, Egypt. E-mail:sbah.ibrahim@yahoo.com

Received date: 23 January 2018, Accepted date: 25 April 2018, Online date: 25 May 2018

\section{A B S T R A C T}

\begin{abstract}
Increasing concentrations of antibiotics including tetracycline chloride in surface and groundwater are a major environmental concern in recent years. In this research, the potential of electric arc furnace dust for efficient removal of tetracycline chloride residue from aqueous solutions was investigated. For this purpose, electric arc furnace dust was characterized by XRD, surface area and TEM techniques. Effect of various parameters such as contact time, adsorbent dosage, initial concentration of tetracycline chloride and temperature on adsorption of tetracycline chloride on electric arc furnace dust was investigated. The results showed that the best condition for removal of tetracycline chloride was exhibited at contact time $120 \mathrm{~min}$ and adsorbent dosage $1 \mathrm{~g} / \mathrm{L}$. the removal of tetracycline chloride decreased with the increase of initial concentration. Langmuir and Freundlich isotherm models were applied to the equilibrium data. Results indicate the potential of electric arc furnace dust for removal of tetracycline chloride from aqueous solutions.
\end{abstract}

Key words: Photodegradation, Tetracycline Chloride, Water, Electric Arc Furnace

\section{INTRODUCTION}

In recent years, the emergence of antibiotics in the environment has received increasing attention. A large number of antibiotic residues are detected in the aquatic ecosystem due to the extensive production and use of antibiotics, and some reports even pointed out that the antibiotic residues were also detected in tap water. The presence of antibiotics in water not only affects the water quality, but also causes potential adverse effects on humans and ecological systems. Although the concentration of antibiotics is very low in the environment (nano $\mathrm{g} \mathrm{L}^{-1}$ or micro $\mathrm{g} \mathrm{L}^{-1}$ ) the antibiotics are hard to be degraded by microorganism due to the complex structure and the antibacterial nature. Hence, antibiotics are gradually enriched in the environment resulting in antibiotic pollution. When long-term exposure to any antibiotic-polluted environment, human health would be affected even at very low concentrations. Among all of the antibiotics, tetracycline (TC) is wildly used in human and veterinary medicine. TC has been detected in sewage water, surface water, groundwater, drinking water, and sludge due to its ineffective removal by conventional water treatment processes. [1]

Tetracycline, sold under the brand name Sumycin among others, is an antibiotic used to treat a number of bacterial infections. This includes acne, cholera, malaria, brucellosis, plague, and syphilis.It is taken by mouth. Common negative effects include vomiting, diarrhea, rash, and loss of appetite.other negative effects include poor tooth development if used by children less than eight years old, kidney problems, and sun burning easily. Use during pregnancy may harm the baby. Tetracycline is in the tetracycline family of medications. It works by blocking the bacteria's ability to make protein [2].

Open Access Journal

Published BY AENSI Publication

(C) 2018 AENSI Publisher All rights reserved

This work is licensed under the Creative Commons Attribution International License (CC BY). http://creativecommons.org/licenses/by/4.0/

\section{(c) (i) Open Access}

To Cite This Article: Sabah S. IbrahimPhotodegradation for Tetracycline Chloride from Water by using Electric Arc Furnace Dust. Research Journal of Fisheries And Hydrobiology, 13(1): 1-12, 2018 
Structure of tetracycline:

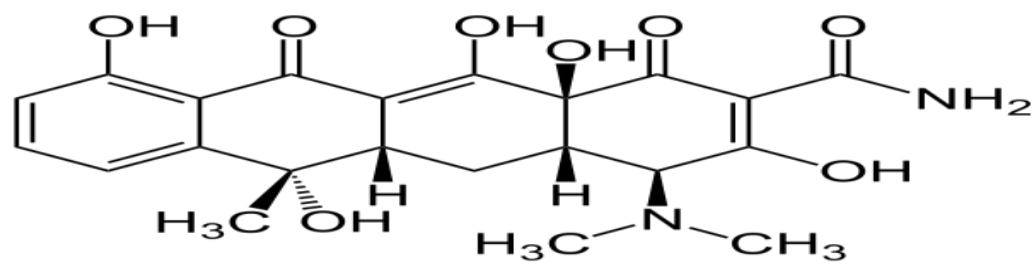

Tetracycline hydrochloride (TC), a well-known class of antibiotics, has been used in animal treatment against infectious diseases, as an additive to animal feeds (poultry, cattle, and swine) in aquaculture, and to inhibit fungal growth in fruit trees as a veterinary medicine. In recent years, concerns have been raised regarding the impact of TC occurrence in theaquatic environment to public health. In a U.S. study, the concentrations of TC residues were found in the influent and effluent of wastewater [3].

The removal of tetracycline hydrochloride by an electrochemical oxidation on $\mathrm{Pb} / \mathrm{PbO}_{2}$ electrode and the feasibility of coupling anodic oxidation-activated sludge culture were examined. The effect of the operating parameters showed that tetracycline hydrochloride (TC) degradation was enhanced for increasing current density and decreasing dye concentrations [4].

Electric arc furnace dust (EAFD) is a solid waste produced during process of steel in steel scrap recycling facilities. It consists mainly of the contaminants of steel and its main components are zinc oxides $(\mathrm{ZnO})$, lead oxide $(\mathrm{PbO})$, and zinc ferrite $\left(\mathrm{ZnFe}_{2} \mathrm{O} 4\right)$. Manganese oxide $(\mathrm{MnO})$ and magnesium oxide $(\mathrm{MgO})$, are contained in smaller amounts as well [5].

Electric arc furnace bag house dust (EAFD), a waste by-product of the steel making process, contains the elements that are volatilized from the charge during the melting $(\mathrm{Cr}, \mathrm{Pb}, \mathrm{Zn}, \mathrm{Cu}$ and $\mathrm{Cd})$. The results of leaching tests show that the concentration of these elements exceed the regulatory limits [6].

\section{Experimental:}

Chemical and Reagents:

All chemicals used in experiment were of analytical grade. Preparation of tetracycline chloride $1 \mathrm{~g} \mathrm{~L}^{-1}$ .EAFD side product and using $1 \mathrm{~g} \mathrm{~L}^{-1}$.

\section{Apparatus:}

SEM spectra were recorded by JSM-6380LA scanning electronX-ray diffraction spectra were recorded by microscope (Jeol) Altima 4 X-Ray diffraction (Rigaco).

\section{Characterization of electric arc furnace dust:}

Using the same characterizing instruments, the SEM image of EAFD adsorbent (Fig. 1) is, to some extent, similar to that of the CKD one, both of them has the irregular structure and the spongy appearance that raise the surface area and free adsorbing sites. The BET of EAFD equals $1.019 \mathrm{~m} / \mathrm{g}$. The XRD patterns of EAFD are shown in Fig. 2. The diffraction peaks are observed at ${ }^{\circ} 2 \theta=31.54,32.42,33.34,34.74,41.10,59.82,60.30$ and 76.50 which are characteristic for EAFD (7). The amorphous nature of the adsorbent is clear from the sharp peaks, and the small diffraction peaks $\left(5^{\circ}-10^{\circ}\right)$ of XRD is used to study the structure of mesoporous adsorbent.

The EDAX composition analysis of EAFD is shown in Table (1). The main ingredient or the major components of EAFD are iron, calcium, oxygen, and carbon. Also, the alkalinity nature of the adsorbent, which raises the solution $\mathrm{pH}$, gives it a good neutralizing ability for acidic media

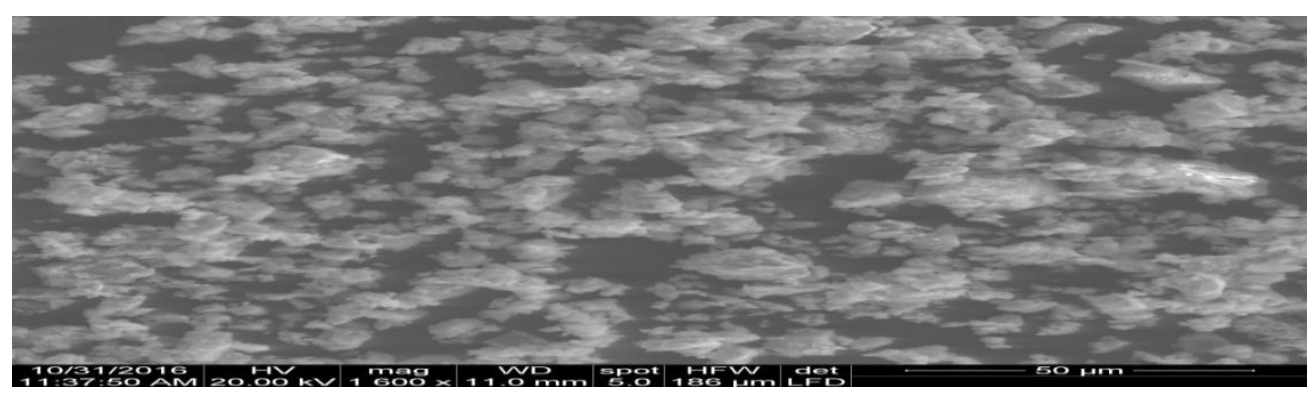

Fig. 1: SEM for Electric Arc Furnace Dust 


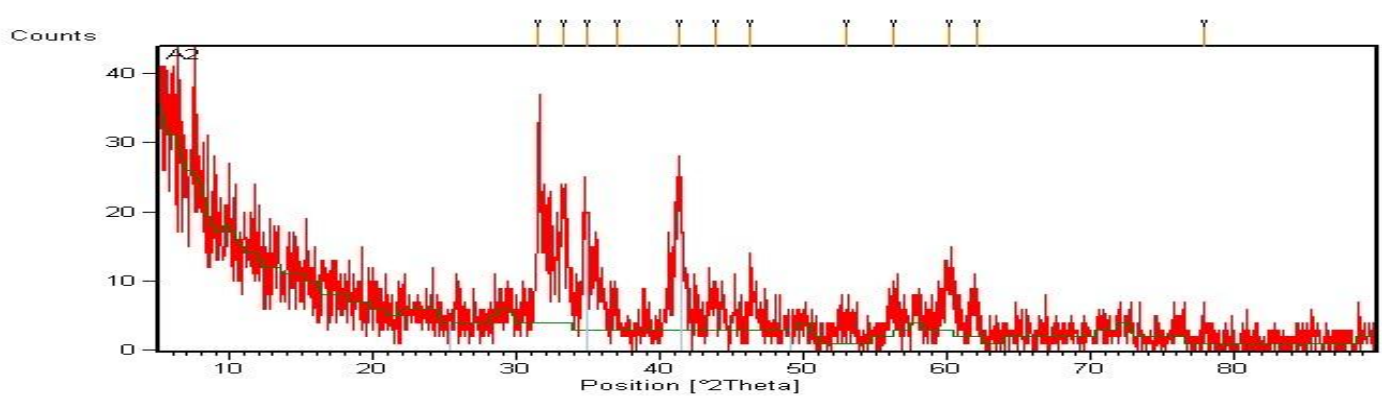

Fig. 2: X ray diffraction for electric furnace dust

Table 1: EDAX ZAF QUANTIFICATION STANDARDLESS SEC TABLE : DEFAUL

\begin{tabular}{|l|l|l|}
\hline Element & Wt $\%$ & At\% \\
\hline Ck & 12.19 & 25.20 \\
\hline Ok & 24.46 & 37.95 \\
\hline Mgk & 1.86 & 1.90 \\
\hline Alk & 3.21 & 2.96 \\
\hline Sik & 3.88 & 3.43 \\
\hline Cak & 24.9 & 15.46 \\
\hline Mnk & 2.74 & 1.24 \\
\hline Fek & 26.71 & 11.87 \\
\hline
\end{tabular}

Batch experiments:

The batch experiments were carried out in $250 \mathrm{ml}$ Erlenmeyer containing $100 \mathrm{ml}$ of aqueous solution. The suspension was shaken in temperature-controlled shaker at $200 \mathrm{rpm}$. The residual concentration of TC in supernatant was analyzed by HACH UV-spectrophotometer at $\lambda$ max value of tetracycline chloride $(569 \mathrm{~nm}$ wavelength). Effects of adsorbent dosage (0.1-0.3 g/L), contact time (10-120 min), initial TC concentration $(100-400 \mathrm{mg} / \mathrm{L})$ and temperature $\left(30 \mathrm{C}^{0}-70 \mathrm{C}^{0}\right)$ on adsorption of tetracycline chloride by electric arc furnace dust were investigated. The adsorption capacity $\mathrm{q}_{\mathrm{e}}(\mathrm{mg} / \mathrm{g})$ of the adsorbent was calculated from

The following equation

$\mathrm{q}_{\mathrm{e}}=(C i-C e) V / W$

Removal efficiency $\%=(C i-C e) 100 / C i$

Where $\mathrm{Ce}$ is the residual concentration reached at equilibrium state, $\mathrm{Ci}$ is initial tetracycline chloride concentration and $V$ is the volume of solution (L) and $W$ is the weight of adsorbent $(\mathrm{g})$.

\section{RESULTS AND DISCUSSION}

Effect of contact time in present UV only on tetracycline chloride:

During direct photolysis, photon absorption gives rise to compounds in excited electronic states that are susceptible to chemical transformation. In UV direct photolysis, the contaminant to be destroyed absorbs the incident radiation and undergoes degradation starting from its excited state [8]. UV irradiation would attack and decompose some organic molecules by bond cleavage and free radical generation, but usually at very low rates [9].

In the presence of UV radiation only, the rate of removal is high for tetracycline in the beginning indicating that degradation for antibiotics is fast during the first period. The removal reached its maximum value at about $120 \mathrm{~min}$ for tetracycline (55\%). The percent of removal is high for tetracycline chloride in the beginning due to a large surface area of the adsorbent being available for the adsorption of the antibiotic. The equilibrium time for this antibiotic was about $120 \mathrm{~min}$. The removal percent at equilibrium was $97 \%$ tetracycline chloride in present UV and electric arc furnace dust. In presence electric arc furnace only reached removal percent to $96 \%$. The two stages sorption mechanism with the first rapid and quantitatively predominant and the second slower and quantitatively insignificant, has been extensively reported in literature [10]. A photochemical reaction is characterized by an activation related to the absorption of at least one photon by a molecule. The range of wavelengths generally used in photochemistry is in the UV/visible region (wavelength 200 to $700 \mathrm{~nm}$ ). However, this is not always sufficient for suitable pollutant remediation. Thus, oxidants such as $\mathrm{O}_{3}, \mathrm{H}_{2} \mathrm{O}_{2}$ and/or a catalyst are often used.

The mechanism of nanoTiO 2 photo catalysis is concluded as follows: $\mathrm{TiO}_{2}$ absorbs UV light to generate electron $\left(\mathrm{e}^{-}\right)$and hole $\left(\mathrm{h}^{+}\right)$. The holes combine with $\mathrm{H}_{2} \mathrm{O}$ on the surface of $\mathrm{TiO}_{2}$ to form $\mathrm{H}^{+}$and $\cdot \mathrm{OH}$ free radicals. $\mathrm{H}^{+}$and electron react to yield $\bullet \mathrm{H}$. The $\bullet \mathrm{H}$ and $\bullet \mathrm{OH}$ free radicals attack the organic molecule, and then 
produce some intermediate products. The mechanism of photo catalytic degradation under UV light irradiation is described by [11]:

$\mathrm{TiO} 2+\mathrm{h} v \rightarrow \mathrm{e}^{-}+\mathrm{h}+$

$\mathrm{h}^{+}+\mathrm{H}_{2} \mathrm{O} \rightarrow \mathrm{H}^{+}+\cdot \mathrm{OH}$

$\mathrm{e}^{-}+\mathrm{H}^{+} \rightarrow \cdot \mathrm{H}$

$\bullet \mathrm{OH}(\cdot \mathrm{H}) \rightarrow \rightarrow$ antibiotic $\rightarrow$ oxidative products $\rightarrow$ end product

When the antibiotic solutions exposed to the UV radiation in the presence of different nano particles under investigation shown in Fig (3)

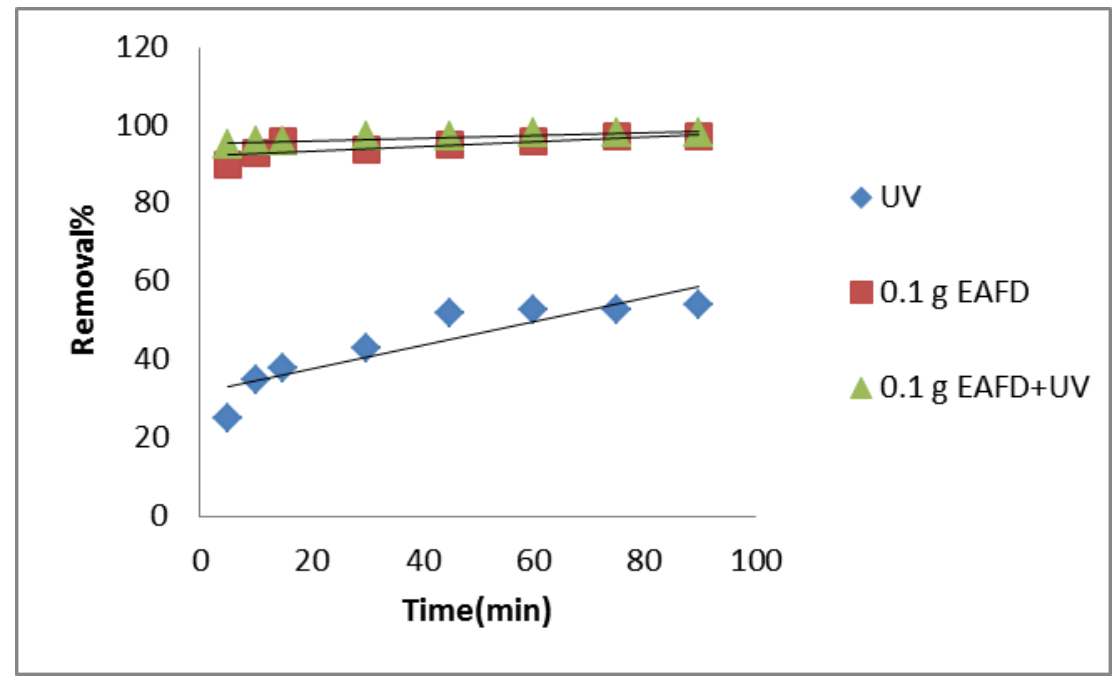

Fig. 3: Effect of time on the percent of tetracycline adsorption in presence of electric arc furnace dust

Effect of different doses from electric furnace dust tetracycline chloride:

Fig.4. illustrates the effect of different amounts of electric arc furnace dust ( 0.1 to $0.3 \mathrm{~g}$ per $100 \mathrm{ml})$ on the removal of tetracycline chloride it is observed that the efficiency of removal increased from $94 \%$ at 10 min but reach removal\% to $81 \%$ at $120 \mathrm{~min}$ at used $0.1 \mathrm{~g}$ ERFD. at use $0.2 \mathrm{~g}$ of EAFD reach removal\% for tetracycline to $97 \%$ at $10 \mathrm{~min}$ and reach to equilibrium state the removal\% to $96 \%$. Another state when using $0.3 \mathrm{~g}$ of EAFD the removal\% of tetracycline reached to $98 \%$ at 10 .

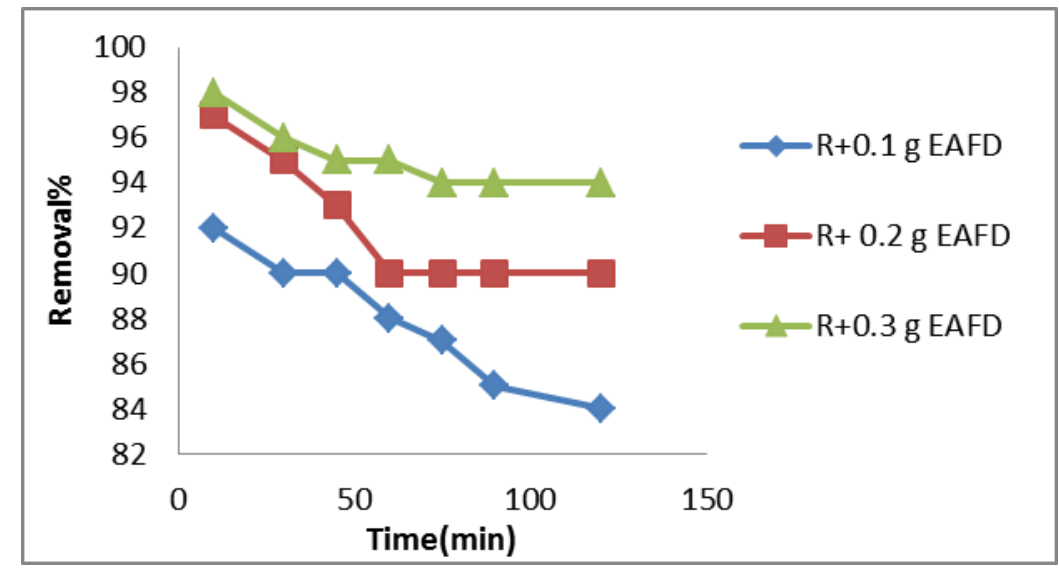

Fig. 4: Effect of different doses of electric furnace dust on tetracycline removal.

\section{Effect of Initial antibiotic Concentration on antibiotic Uptake:}

The antibiotic uptake mechanism is particularly dependent on the initial antibiotic concentration: at low concentrations, antibiotics are adsorbed by specific sites, while with increasing antibiotics concentrations the specific sites are saturated, and the exchange sites are filled. It is observed that with increasing initial concentrations, the adsorption capacity increases while the percent antibiotic removal decreases. Though an 
increase in antibiotic uptake was observed, the decrease in percentage adsorption may be attributed to lack of sufficient surface area to accommodate much more antibiotics available in the solution. At lower concentrations, the antibiotic present in solution could interact with the binding sites and thus the percentage adsorption was higher [12]. The general shapes of the isotherms are similar for different biomasses. However, the adsorption capacities and affinities are significantly different.

In the same time, literature showed that adsorption is independent of the contaminant concentration, and in some cases, the rate is lowered with increased initial concentration [13]. Different explanations were proposed, all of which rely on the adsorption of contaminant molecules on the solid surface. One explanation assumed that at higher contaminant concentration, the contaminant molecules may compete with the adsorbed intermediates and inhibit degradation [14].

Effect of antibiotic concentration removal by electric arc furnace dust in present of UV lamp:

The effect of initial antibiotic concentration on the rate of antibiotic uptake onto electric arc furnace dust was studied using batch agitation in $250 \mathrm{ml}$ beakers containing antibiotic solutions of initial concentrations ranging from 100 to $300 \mathrm{mg} \mathrm{L}^{-1}$, agitated at $250 \mathrm{rpm}$ and at room temperature $\left(25 \pm 1^{\circ} \mathrm{C}\right)$ without any change in the initial $\mathrm{pH}$ of the test solution. The equilibrium concentration was evaluated after 120 min of contact time. The photo degradation for tetracycline is presented in Fig. (5) Indicating that the percentage removal of tetracycline chloride decreases with increase in initial tetracycline chloride concentration. to reach removal\% up to $96 \%$ at concentration $0.1 \mathrm{~g}$ of tetracycline chloride.

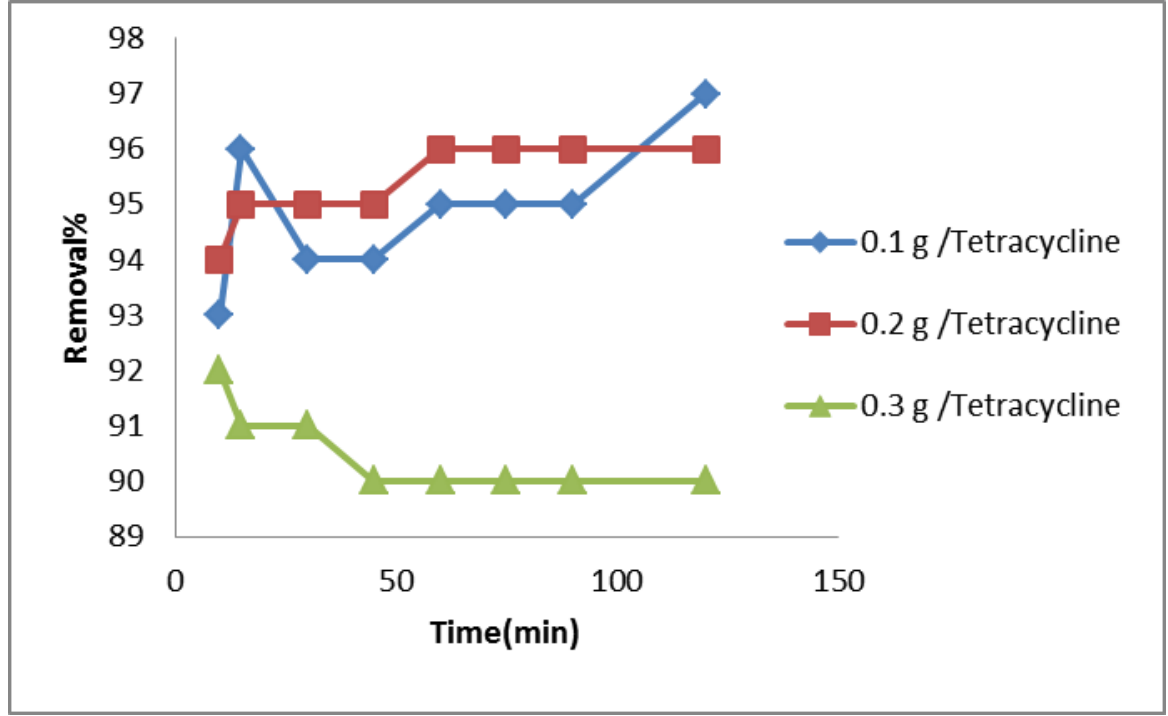

Fig. 5: Effect of different concentration of tetracycline chloride in present mercury lamp. Effect of $\mathrm{pH}$ on photo degradation of tetracycline chloride:

Effect of $\mathrm{pH}$ on photo degradation of tetracycline chloride on surface of electric arc furnace dust are variable and give maximum degradation to reach removal percent $97 \%$ at natural $\mathrm{PH}=4.5$ as shown in fig(6)

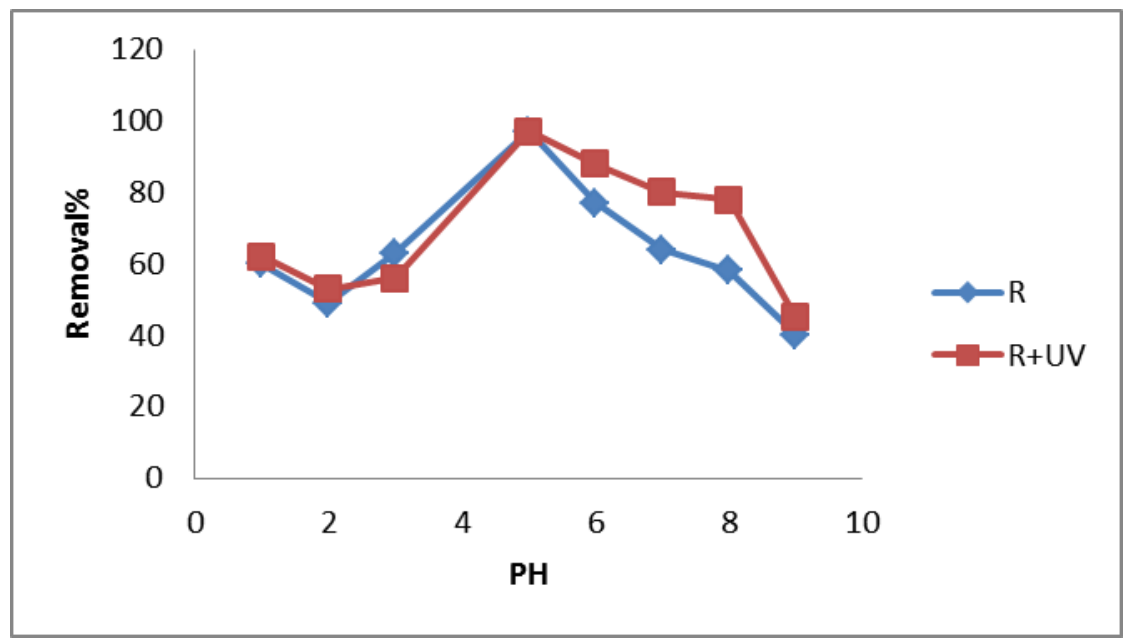

Fig. 6: Effect of $\mathrm{pH}$ on removal tetracycline chloride by using electric arc furnace dust 
Effect of stirring on tetracycline chloride by electric furnace dust:

The stirring effect on removal efficiency for tetracycline chloride during photo adsorption processes was examined by varying the stirring rate from 100 to $500 \mathrm{rpm}$. The remaining concentration of antibiotic was measured after $120 \mathrm{~min}$ of continuous stirring at 100, 200, 300, 400 and $500 \mathrm{rpm}$. Adsorption for tetracycline chloride increased by increasing stirring and reached to $94 \%$. But in present UV lamp the removal percentage reach to $98 \%$ at $500 \mathrm{rpm}$. in fig (7).

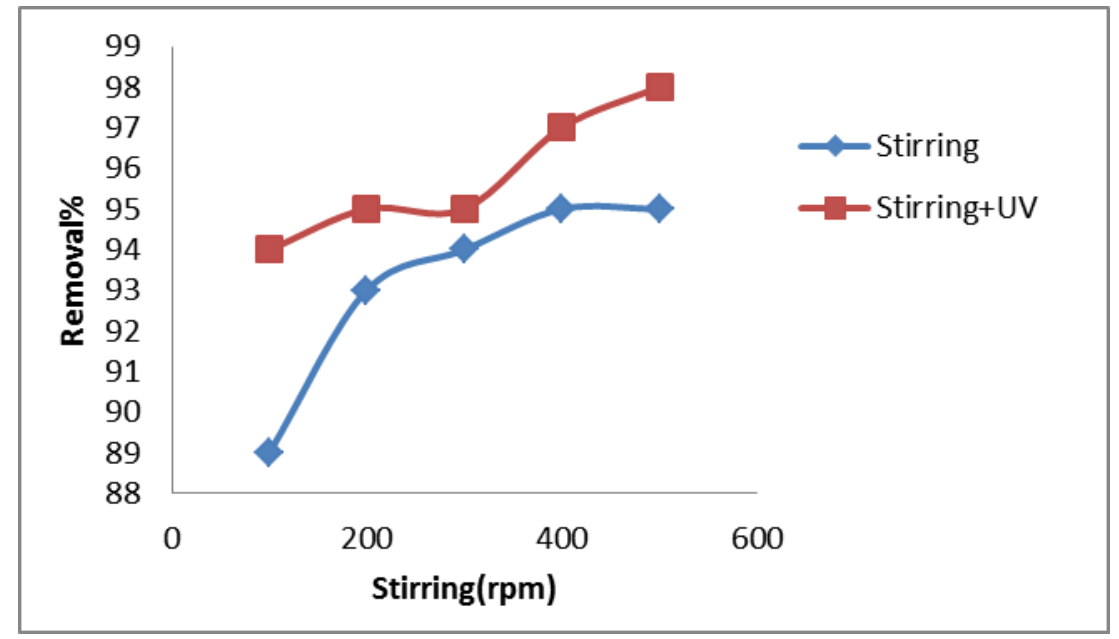

Fig. 7: Effect of stirring on removal of tetracycline chloride by using electric arc furance dust

Effect of temperature on removal tetracycline chloride in present UV lamp:

The temperature of the medium could be important for energy-dependent mechanisms in the removal efficiency by different materials. The reason of this effect is thought to be the fact that temperature is an important factor affecting the adsorption and photo catalysis. In the case of photo catalytic process, the photo catalytic degradation rate increases with increasing temperature. In other words, higher temperature provides higher electron transfers in valance bond to higher energy levels and hence facilitating the electron-hole production that could be utilized in initiating oxidation and reduction reactions [15]. The species photongenerated holes, and electrons, and hydroxyl radicals $(\bullet \mathrm{OH})$ can thus degrade organic pollutant to intermediates, and then the intermediates are further degraded to $\mathrm{CO}_{2}$ and $\mathrm{H}_{2} \mathrm{O}$.

In general, the activated energy of photo catalytic reaction is slightly affected by the temperature, but consecutive redox reaction may be significantly influenced by temperature which affects both collision frequency of molecules and adsorption equilibrium [16]. So, the overall effect on the photo catalytic performance will depend on the relative importance of these phenomena. It was observed that the percentage removal tetracycline chloride decrease by increase temperature at $25^{\circ} \mathrm{c}$ when percentage removal was $99 \%$ and then decreased to $93 \%$ at $70^{\circ} \mathrm{c}$. while the removal percentage was increased with used UV lamp to $93 \%$ at $30^{\circ} \mathrm{c}$ and $97 \%$ at $70^{\circ} \mathrm{c}$.

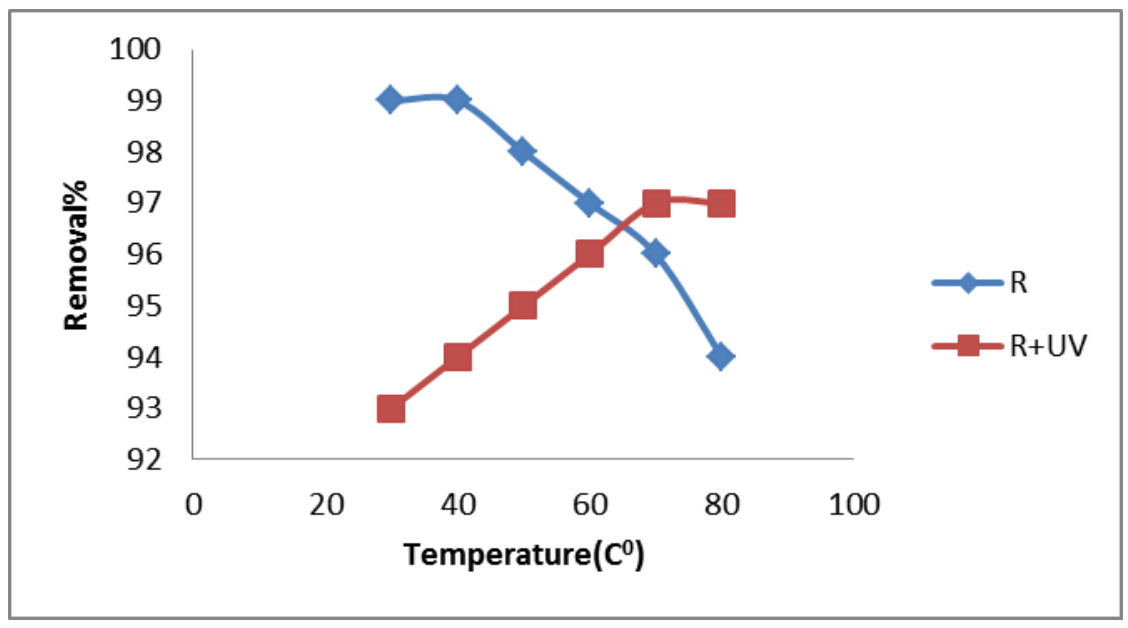

Fig. 9: Effect of temperature on removal of tetracycline chloride by using electric arc furance dust 
In order to evaluate the thermodynamic feasibility of the removal process and to confirm the nature of the adsorption process, thermodynamic parameters $\left(\Delta \mathrm{G}^{\mathrm{o}}, \Delta \mathrm{H}^{\mathrm{o}}\right.$ and $\left.\Delta \mathrm{S}^{\circ}\right)$ were calculated from the following equations $[17,18]$ :

$K_{D}=\frac{C_{A d}}{C_{e}}$

$\Delta G=-R T \ln K_{D}$

$\ln K_{D}=-\left(\frac{\Delta H}{R T}\right)+\frac{\Delta S}{R}$

where $K_{D}$ is the equilibrium constant, $C_{A d}(\mathrm{mg} / \mathrm{L})$ is the concentration of the tetracycline chloride adsorbed on solid at equilibrium, $\mathrm{C}_{\mathrm{e}}(\mathrm{mg} / \mathrm{L})$ is the equilibrium concentration of tetracycline in the solution, $R$ is the universal gas constant, $8.314 \mathrm{~J} / \mathrm{mol}^{-1} / \mathrm{K}$, $\mathrm{T}$ is the absolute temperature in $\mathrm{K}$, and the value of $\mathrm{K}_{\mathrm{D}}$ in can be obtained from the adsorption percent at equilibrium. The values of $\Delta \mathrm{H}$ and $\Delta \mathrm{S}$ can be obtained from the slope and intercept of a van't Hoff plot of $\ln K_{D}$ versus $1 / T$ as seen in Fig 10. the thermodynamic parameters need for adsorption of tetracycline chloride in electric arc furnace dust are listed in Tables 3.

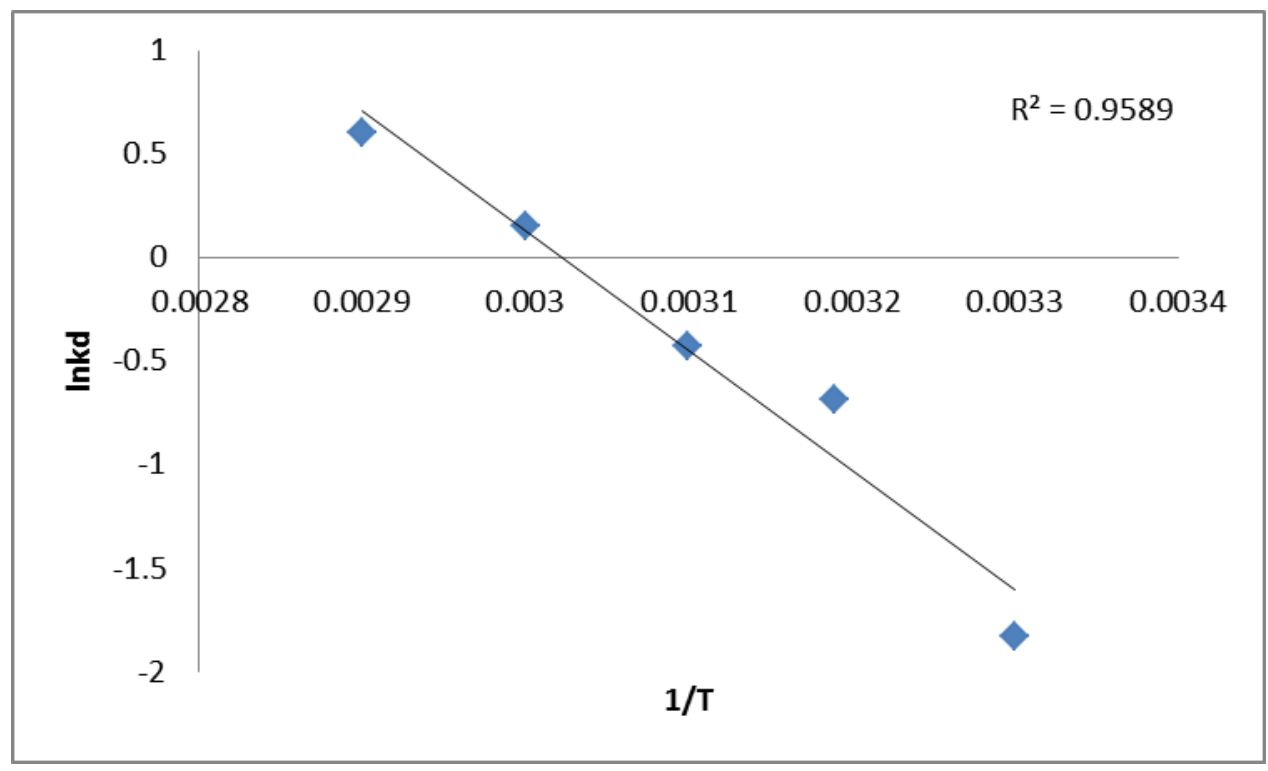

Fig. 10: Effect of temperature on removal tetracycline chloride by using electric arc furnace dust

Table2: Effect of temperature on removal for tetracycline chloride

\begin{tabular}{|l|l|l|l|l|l|}
\hline $\mathrm{T}$ & $1 / \mathrm{T}$ & Removal\% & $\mathrm{K}_{\mathrm{D}}$ & $\ln \mathrm{K}_{\mathrm{D}}$ & $R^{2=} 0.954$ \\
\hline 303 & $3.30 \times 10^{-3}$ & 99 & 0.16 & -1.83 & \\
\hline 313 & $3.195 \times 10^{-3}$ & 98 & 0.16 & -1.83 & intercept $=18.4$ \\
\hline 323 & $3.096 \times 10^{-3}$ & 97 & 0.50 & -0.69 & \multirow{2}{*}{ slope $=-6077$} \\
\hline 333 & $3.003 \times 10^{-3}$ & 96 & 0.66 & -0.415 & \\
\hline 343 & $2.90 \times 10^{-3}$ & 92 & 1.16 & 0.148 & \\
\hline 353 & $2.83 \times 10^{-3}$ & 90 & 1.60 & 0.470 & \\
\hline
\end{tabular}

Table 3: Thermodynamic parameters for tetracycline chloride

\begin{tabular}{|l|l|l|l|l|l|l|}
\hline $\begin{array}{l}\Delta \mathrm{H} \\
\mathrm{kJ} / \mathrm{mol}\end{array}$ & $\Delta \mathrm{S}$ & $\Delta \mathrm{G} \mathrm{kJ} / \mathrm{mol}$ & $323 \mathrm{k}$ & $333 \mathrm{k}$ & \\
\cline { 2 - 8 } & $\mathrm{J} / \mathrm{mol}$ & $303 \mathrm{k}$ & $313 \mathrm{k}$ & -1.122 & -0.390 & 0.280 \\
\hline-50532 & -153 & -4.610 & -1.795 & 343 & \\
\hline
\end{tabular}

Adsorption may take place through a multi-step mechanism comprising: (i) external film diffusion; (ii) intraparticle diffusion and (iii) interaction between adsorbate and active site. To define the rate determining step, the uptake/time data was treated according to the Fickian diffusion law [19] where qt is the uptake value at time $(\mathrm{t}), \mathrm{kd}$ if is intraparticle diffusion rate constant ( $\mathrm{mmol} / \mathrm{g}$ min-0.5) and $\mathrm{Xi}$ is the intercept of the straight line which is proportional to the boundary layer thickness. Figure $\mathbf{1 1}$ 


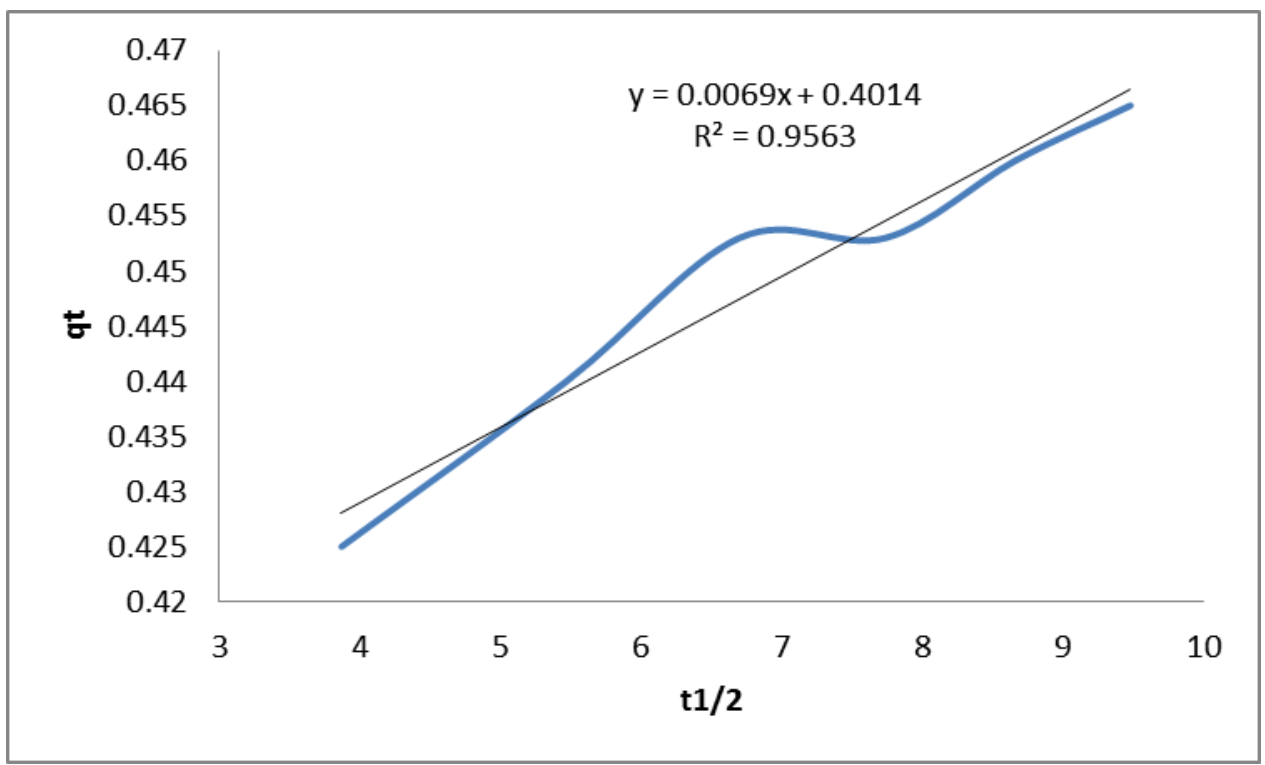

Fig. 11: Relationship between $q t$ and $t_{\frac{1}{2}}$ for tetracycline chloride

\section{Adsorption Isotherms:}

The adsorption isotherm indicated how the adsorption molecules distribute between the liquid phase and the solid phase when the adsorption process reaches an equilibrium state. The analysis of the isotherm data by fitting them to different isotherm models is an important step to find the suitable model that can be used for design purpose. The isotherm data were fitted to the Langmuir and Freundlich isotherms.

\section{The Langmuir Model:}

The Langmuir adsorption isotherm has been successfully applied to many pollutants adsorption processes and has been the most widely used sorption isotherm for the sorption of a solute from a liquid solution [20]. The saturated monolayer isotherm can be represented as:

$q_{e}=\frac{Q_{0} b C_{e}}{1+b C_{e}}$

The above equation can be rearranged to the common linear form:

$\frac{C_{e}}{q_{e}}=\frac{1}{Q_{0} b}+\frac{C_{e}}{Q_{0}}$

Where $C_{\mathrm{e}}$ is the equilibrium concentration $(\mathrm{mg} / \mathrm{L}) ; q_{\mathrm{e}}$ is the amount of antibiotic adsorbed per unit mass of adsorbent ( $\mathrm{mg} / \mathrm{g}) ; Q_{0}$ is $q_{\mathrm{e}}$ for a complete monolayer $(\mathrm{mg} / \mathrm{g})$, a constant related to sorption capacity; and $b$ is a constant related to the affinity of the binding sites and energy of adsorption $(\mathrm{L} / \mathrm{mg})$. A high $b$ value indicates a high affinity. The values of $Q_{0}$ and $b$ were for all adsorbents determined respectively from intercept and slopes of the linear plots of $C_{\mathrm{e}} / q_{\mathrm{e}}$ vs. $C_{\mathrm{e}}$.

The essential characteristics of Langmuir isotherm can be expressed by a dimensionless constant called equilibrium parameter $R_{\mathrm{L}}$, defined by [21]:

$R_{L}=\ln K_{F}+\frac{1}{n} \ln C_{e}$

The value of $R_{\mathrm{L}}$ indicates the type of the isotherm to be either unfavorable $\left(R_{\mathrm{L}}>1\right)$, linear $\left(R_{\mathrm{L}}=1\right)$, favorable $\left(0<R_{\mathrm{L}}<1\right)$ or irreversible $\left(R_{\mathrm{L}}=0\right)$.

Langmuir Adsorption Isotherm for Electric Arc Furnace Dust:

The different adsorption parameters for adsorption of tetracycline chloride are collected in Table4. These parameters are $C_{0}, C_{\mathrm{e}}, \ln C_{\mathrm{e}}, q_{\mathrm{e}}, \ln q_{\mathrm{e}}$ and $C_{\mathrm{e}} / q_{\mathrm{e}}$. The plot of $C_{\mathrm{e}}$ vs. $C_{\mathrm{e}} / q_{\mathrm{e}}$ gave straight lines for all antibiotics Fig. (11), from their slopes and intercepts, the values of $Q_{0}$ and $b$ could be evaluated, respectively.

Table 4: Adsorption parameters of antibiotics on EAFD

\begin{tabular}{|c|l|l|l|l|l|l|}
\hline Antibiotic & $C_{0}$ & $C_{\mathrm{e}}$ & $\ln C_{\mathrm{e}}$ & $q_{\mathrm{e}}$ & \multicolumn{1}{l|}{$C_{\mathrm{e}} / q_{\mathrm{e}}$} \\
\hline Tetracycline Chloride & 1 & 0.4 & -1.66 & 0.8 & -2.3 & 0.5 \\
& 2 & 0.8 & -1.60 & 1.2 & 0.18 \\
& 3 & 1.6 & -0.916 & 1.5 & 0.4 & 0.66 \\
& 4 & 3.0 & -.3566 & 2 & 1.067 \\
& & & & & & 0.69 \\
\end{tabular}




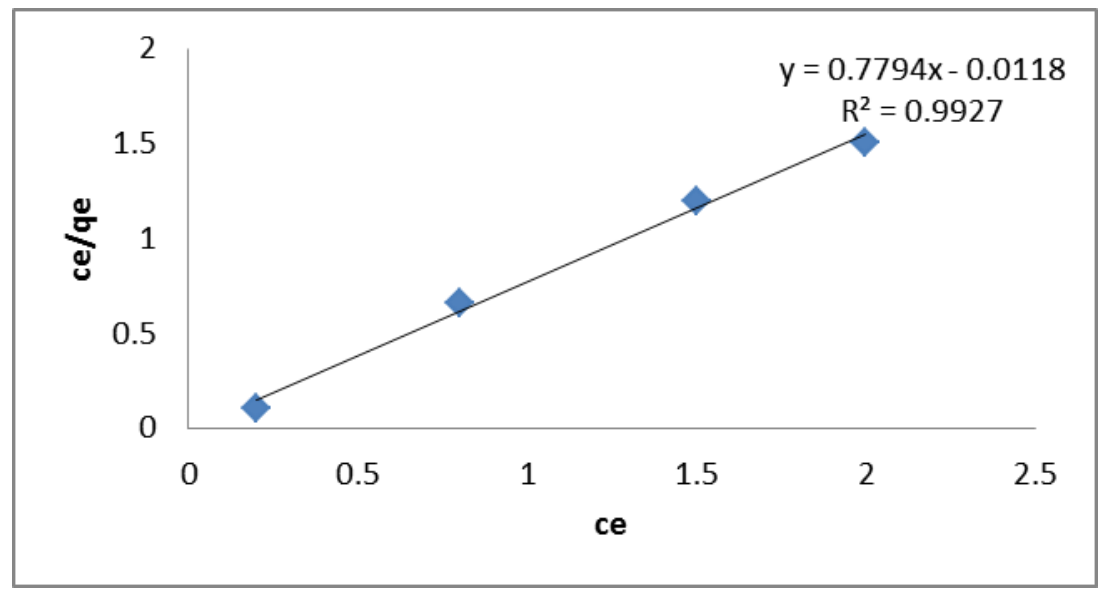

Fig. 11: Langmuir isotherm for tetracycline chloride with electric arc furnace dust

The data obtained for slope, intercept, $Q_{0}$ and $b$ are shown in Table 5. The applicability of the model was examined by evaluating the correlation coefficient $(R)$. The higher the values of $R$, the more applicable the model for the antibiotic examined.

Table 5: Langmuir equation parameters for EAFD

\begin{tabular}{|l|l|l|l|l|l|}
\hline Antibiotics & Slope & Intercept & $Q_{0}$ & $b$ & $R^{2}$ \\
\hline Tetracycline chloride & 0.779 & 0.15 & 1.013 & 5 & 0.992 \\
\hline
\end{tabular}

The Freundlich Model:

On the other hand, the Freundlich isotherm assumes that the adsorption occurs on heterogeneous surface at sites with different energy of adsorption and with non-identical adsorption sites that are not always available. Mathematically it is characterized by the heterogeneity factor " $1 / n$ " [22]. Freundlich model can be represented by the linear form as follows:

$\ln q_{e}=\ln K_{\mathrm{F}}+\frac{1}{n} \ln C_{e}$

Where $K_{\mathrm{F}}$ is the Freundlich constant $(\mathrm{mg} / \mathrm{g}) /(\mathrm{L} / \mathrm{mg})^{n}$ and $n$ is the heterogeneity factor. The $K_{\mathrm{F}}$ value is related to the adsorption capacity; while $1 / n$ value is related to the adsorption intensity. A plot of $\ln q_{\mathrm{e}}$ versus $\ln C_{\mathrm{e}}$, gives a straight line with $K_{\mathrm{F}}$ and $1 / n$ determined from the intercept and the slope, respectively.

\section{Freundlich adsorption Isotherm for EARF.:}

The adsorption isotherm was applied for adsorption tetracycline chloride by drawing the relation between $\ln C_{\mathrm{e}}$ and $\ln q_{\mathrm{e}}$ Fig. (12) The slope of the resulting straight line is equals to $1 / n$, while the intercept equals to $\ln K_{\mathrm{F}}$. The data obtained for Freundlich isotherm model for tetracycline chloride are collected in Table 4. The calculated Freundlich isotherm constants and the corresponding coefficient of correlation values are shown in Table6. The coefficient of correlation was high $\left(R^{2}\right.$ values are 0.997$)$ indicating a good linearity. The results show that the values of $\mathrm{n}$ are greater than unity $(n)$ indicating that antibiotic is favorably adsorbed on tetracycline chloride. Of Freundlich constants indicate easy uptake of antibiotic from aqueous solution.

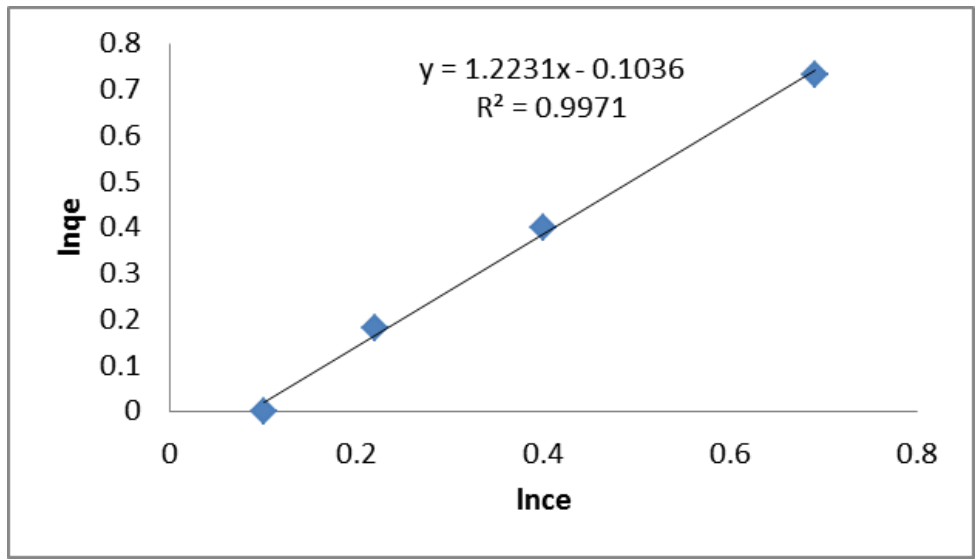

Fig. 12: Freundlich isotherm for tetracycline chloride with EAFD 
Table 6: Freundlich equation parameters for EAFD

\begin{tabular}{|l|l|l|l|l|l|}
\hline Antibiotics & Slope & Intercept & $K_{\mathrm{F}}$ & $n$ & $R^{2}$ \\
\hline Tetracycline chloride & 1.22 & 0.10 & 0.40 & 0.775 & 0.997 \\
\hline
\end{tabular}

Kinetic Studies:

The pseudo-first order equation is generally expressed as follows [23]:

$\log \left(q_{e}-q_{t}\right)=\log q_{e}-\left(\frac{k_{1}}{2.303}\right) \mathrm{t}$

Where $q_{\mathrm{e}}$ and $q_{t}$ are the sorption capacities at equilibrium and at time $t$, respectively $\left(\mathrm{mg} \mathrm{g}^{-1}\right)$ and $k_{1}\left(\mathrm{~min}^{-1}\right)$ is the rate constant. The equation applicable to experimental results generally differs from a true first order equation in two ways: (i) the parameter $\log \left(q_{\mathrm{e}}-q_{t}\right)$ does not represent the number of available sites and (ii) the parameter $\log (q \mathrm{e})$ is an adjustable parameter and often it is found not equal to the intercept of a plot of $\log$ $(q \mathrm{e}-q t)$ against $t$, whereas in a true first order $\log \left(q_{\mathrm{e}}\right)$ should be equal to the intercept of a plot of $\log \left(q_{\mathrm{e}}-q_{t}\right)$ against $t$. In order to fit the pseudo-first order equation to experimental data, the equilibrium capacity, $q_{\mathrm{e}}$ must be known.

On the other hand, if the rate of degradation is a second-order mechanism, the pseudo-second order kinetic rate equation is expressed as:

$\frac{\mathrm{t}}{q_{t}}=\frac{1}{\mathrm{k}_{2} \mathrm{q}_{\mathrm{e}}^{2}}+\frac{1}{q_{e}}$

Where $q$ e and qtare the sorption capacities at equilibrium and at time $t$, respectively $\left(\mathrm{mg} \mathrm{g}^{-1}\right)$ and $k$ is the rate constant of pseudo-second order reaction $\left(\mathrm{g} \mathrm{mg}^{-1} \mathrm{~min}^{-1}\right)$.

If pseudo-second-order kinetics are applicable, the plot of $t / q_{t}$ against $t$ should give a linear relationship, from which $q$ e and $k_{2}$ can be determined from the slope and intercept of the plot.

Table 7: Photodegardation parameters of tetracycline chloride on electric arc furnace dust

\begin{tabular}{|l|l|l|}
\hline Antibiotic & $\log \left(\mathrm{q}_{\mathrm{e}}-\mathrm{q}_{\mathrm{t}}\right)$ & $\mathrm{T}(\mathrm{min})$ \\
\hline & & \\
Tetracycline & -0.55 & 15 \\
& -0.69 & 30 \\
& -1 & 45 \\
& -1 & 60 \\
\hline
\end{tabular}

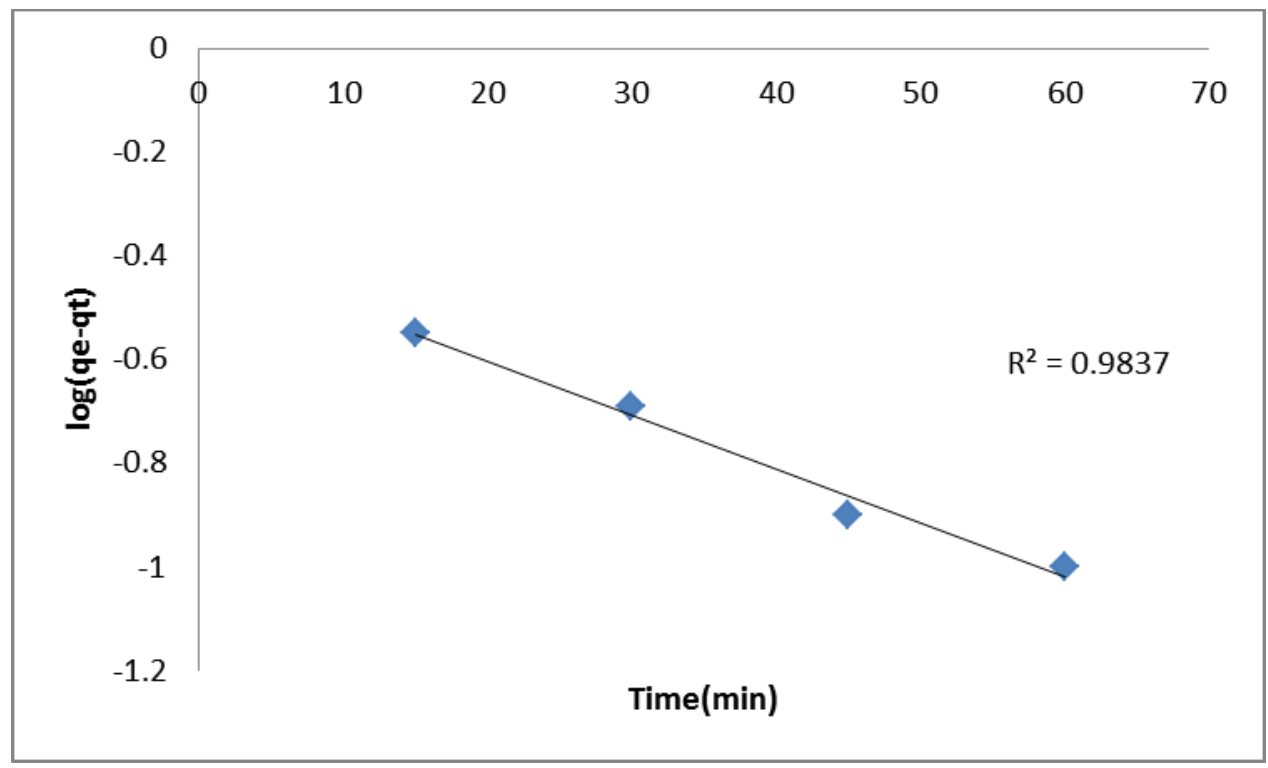

Fig. 13: The pseudo-first order for tetracycline chloride on EAFD

\section{Conclusion:}

Heterogeneous photo catalysis using electric furnace dust as photo catalyst was proven to be an effective method for the degradation of tetracycline chloride in its aqueous solution. The experimental results demonstrated that increasing the substrate concentration, light exposure period, and electric arc furnace dust dosage in an appropriate range contributed to the photo catalytic degradation of tetracycline. The removal of the antibiotic by adsorption on electric arc furnace dust was found to follow fresundlich and Langmuir isotherm 
models. The rate of photo degradation follows pseudo first order with a rate constant $-0.16 \mathrm{~min}^{-1}$ for tetracycline chloride

\section{REFERENCES}

1. Liu. Zhimeng, Zhu. Mengfu, Zheng Wang, Hong Wang, Cheng Dengand KuiLi, 2016. Effective Degradationof Aqueous Tetracycline UsingaNano-TiO2/Carbon Electrocatalytic Membrane, Journalof Materials.

2. Ray. Lengel, Guide to Understanding Antibiotics Prescribed in Your Doctor's Office Medical Schoo, North Ridgeville, $\mathrm{OH} 44039$ APUA.

3. Yan Ma, Nai. Gao, Li. Cong, 2012. Degradation and Pathway of Tetracycline Hydrochloride in Aqueous Solution by Potassium Ferrate, Environmental Engineering Science., 29.

4. Idris. Yahiaoui Farida, Ais. Benissada, Flo. fourcade, 2013. Abd. Amraneb, Removal of tetracycline hydrochloride from water based on direct anodic oxidation $(\mathrm{Pb} / \mathrm{PbO} 2$ electrode) coupled to activated sludge culture, Chemical Engineering Journal., 221: 418-425.

5. Fujimoto, b. Katsuya Maruyama, a. Takahiro Miki, Tetsuya Nagasaka, 2016. The selective alkaline leaching of zinc oxide from Electric Arc Furnace dust pre-treated with calcium oxide Romchat, Japan Hydrometallurgy, 159: 120-125.

6. Youcai, Z., R. Stanforth, 2000. Integrated hydrometallurgical process for production of zinc from electric arc furnace dust in alkalin medium, Journal of Hazardous Materials, 80(1): 223-240.

7. Rayed Shawabkeh, A., F. Maha Tutunji, 2003. "Experimental study and modeling of basic dye sorption by diatomaceous" Applied Clay Science., 24(1): 111-120.

8. Parsons, S., 2004. Advanced Oxidation Processes for Water and Wastewater Treatment, IWA Publishing, London, UK..

9. Scheck, C.K., F.H. Frimmel, 1995. Degradation of phenol and salicylic acid by ultraviolet radiation/hydrogen peroxide/oxygen, Water Res., 29: 2346-2352.

10. Konstantinou, I.K., T.A. Albanis, 2004. $\mathrm{TiO}_{2}$-assisted photocatalytic degradation of azodyes in aqueous solution: Kinetic and mechanistic investigations. A review. Applied Catalysis B Environmental., 49: 1-14.

11. Wu, R., J. Qu, Y. Chen, 2005. Magnetic powder MnO-Fe2O3 composite-a novel material for the removal of azo-dye from water, Water. Research, 39: 630-638.

12. Saha, S., J.M. Wang, A. Pal, 2012. Nano silver impregnation on commercial TiO2 and a comparative photocatalytic account to degrade malachite green, Sep. Purification and Technology, 89: 147-155.

13. Qourzal, S., M. Tamimi, A. Assabbane, 2005. Y. Ait-Ichou Photocatalytic degradation and adsorption of 2naphthol on suspended $\mathrm{TiO}_{2}$ surface in a dynamic reactor, J.Colloid Interface Science., 286: 621-626.

14. Gupta, V.K., R. Jain, A. Mittal, T.A. Saleh, A. Nayak, S. Agarwal, S. Sikarwar, 2012. Photo-catalytic degradation of toxic dye amaranth on $\mathrm{TiO}_{2} / \mathrm{UV}$ in aqueous suspensions, Material. Science. Engeering, 32: 12-17.

15. Saien, J., H. Nejati, 2007. "Enhanced photocatalytic degradation of pollutants in petroleum refinery wastewater under mild conditions," J. Hazard. Material, 148: 491-495.

16. Wenhua, L., L. Hong, C. Saóan, Z. Jianqing and C. Chunan, 2000. "Kinetics of photocatalytic degradation of aniline in water over TiO2 supported on porous nickel," J. Photochemistry and Photobiology., A, 131: 125-132.

17. Bubacz, K., J. Choina, D. Dolat, A.W. Morawski, 2010. "Methylene Blue and Phenol Photocatalytic Degradation on Nanoparticles of Anatase TiO2", Polish J. of Environmetal Study, 19(4): 685-691.

18. Shipra Mital, G., T. Manoj., 2011. "A review of TiO2 nanoparticles", Chinese Science Bulletin, 56(16): 1639-1657.

19. Guibal, E., C. Milot and J.M. Tobin, 1998. Metal-anion sorption by chitosan beads: Equilibrium and kinetic studied, Ind. Eng. Chem. Res., 37: 1454-1463.

20. Salinaro, A.V. Emeline, J. Zhao, H. Hidaka, V.K. Ryabchuk, N. Serpone, 2012. Ter-minology, relative photonic efficiency and quantum yields in heterogeneous photocatalysis. Part II. Experimental., pp: 200202.

21. Li, D., Y.N. Xia, 2004. Electrospinning of nanofibers: reinventing the wheel? Advanced Materials. 16: 1151-1170.

22. Ramakrishna, S., K. ujihara, W.E. Teo, T. Yong, Z.W, Ma, R. Ramaseshan, 2006. Electrospunnanofibers: solving global issues. Materials Today, 9: 40-50.

23. Chern, J.M., C.Y. Wu, 2001. Desorption of dye from activated carbon beds: effects of temperature, $\mathrm{pH}$ and alcohol, Water Research, 35: 4159-4165. 